\title{
An Intelligent Energy Metering Using Zigbee and Arm7
}

\author{
Mr. Sarwade Narasing J., Mr. Dehadray Bhushan M., Mr. Khedkar Sachin T., \\ Mr. Turkane S. S. \\ PREC, Loni (BE E\&TC)
}

\begin{abstract}
Traditional meter reading for electricity consumption and billing is done by human operator from houses to houses and building to building. This requires huge number of labor operators and long working hour to achieve complete area data reading and billing. Human operator billing or prone to reading error as sometime the houses electric power meter is place in a location where it is not easily accessible. The concept is to reduce the time delay. Hence it need not wait for the slack time of other previously task .The power management system is consists of Zigbee Digital Power meters installed in every consumer unit and an Electricity e-Billing system at the energy provider side. The Zigbee Digital Power meter (ZPM) is a single phase digital kWh power meter with embedded Zigbee modem which utilize the Wireless sensor network to send its power usage reading using information back to the energy provider wirelessly.
\end{abstract}

\section{Introduction}

An embedded electric meter consisting of zigbee communication and ARM7 processor is developed to obtain meter reading automatically. Energy metering IC along with ARM processor is used to convert the energy consumption into meter reading. Zigbee module is used obtain measured energy consumption on personal Computer. Mobile which is interfaced to the personal computer is used to send bill message to the customer.

It is comprised of Zigbee network and database management system, has many important advantages such as low cost, low system power consumptions. Also it reduce the reading mistake, has the advantage of high speed and good real -time. With the project of the wireless Electric Meter reading for wireless communication technology, complete the design of automatic Electric Meter reading system. The major difference between Zigbee data acquisition system and other data collector is that it realizes wireless data transmission after the A/D conversion .Zigbee technology is a short-range wireless communications technology. It has developed rapidly in recent years. Data acquisition which is based on sensor technology, signal detection and processing. This system has advantages such as portability, reliability and high accuracy.

\section{System Architecture}

An automatic meter reading system based on ARM7 and zigbee technology is proposed for solving problems of the existing metering system. Zigbee module is used as an interface between ARM controller and pc mobile is used to send bill message to the customer.

The system is designed for measuring electrical bill wirelessly \&sends the information of bill to consumer. The energy consumed can then observed and stored on PC. The software to calculate the bill is stored on PC which then calculates the bill in rupees depending on the tariff .Mobile which is interfaced to the personal computer is used to send bill message to the customer \& deadline for the paying bill.

Basically system having two parts transmitting section and receiving section.

A] Transmiting Section-

Transmitting section of this system contains energy meter, ARM 7, LCD, relay, power supply parts and zigbee module.

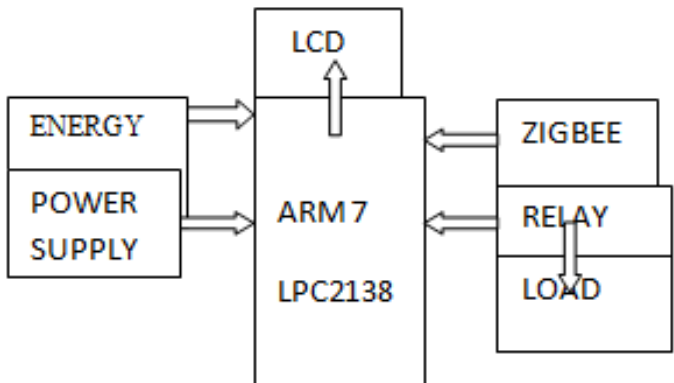

Fig1-Transmiting Section of System 


\section{B] Receiving Section-}

Receiving section of this system contains zigbee receiver module, computer, and mobile for sending the bill to consumer.

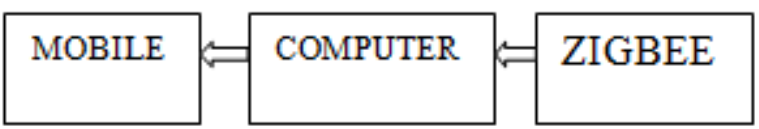

Fig2- Receiving Section

Hardware design of system contains

\section{Hardware Design}
a] ARM7(LPC2148)
b] Energy Meter
c] Zigbee Unit
d] Relay Unit
e] Mobile Section

\section{a] ARM7(LPC2138)-}

The LPC2138 microcontrollers are based on a 16/32-bit with real-time emulation and that combine the microcontroller with $32 \mathrm{~kb}, 64 \mathrm{~kb}, 256 \mathrm{~kb}$ and $512 \mathrm{~kb}$ of embedded high-speed flash memory .In this system all the digital pulses are given to ARM controller. The ARM controller LPC2138 is programmed such that it accurately measures the amount of energy consumed in units. The zigbee module is interfaced to ARM controller and using this it display the energy consumed on LCD. Also connection of relay is connected to ARM. All the programming part of this system comes under this.

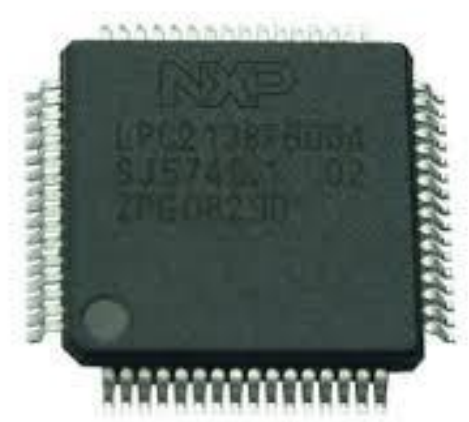

Fig- LPC 2138

It having 8-channel 10-bit ADCs provide a total of up to 16 analog inputs, with conversion times as low as $2.44 \mathrm{~ms}$ per channel. Also having single 10-bit DAC provides variable analog output.

\section{b] ENERGY METER-}

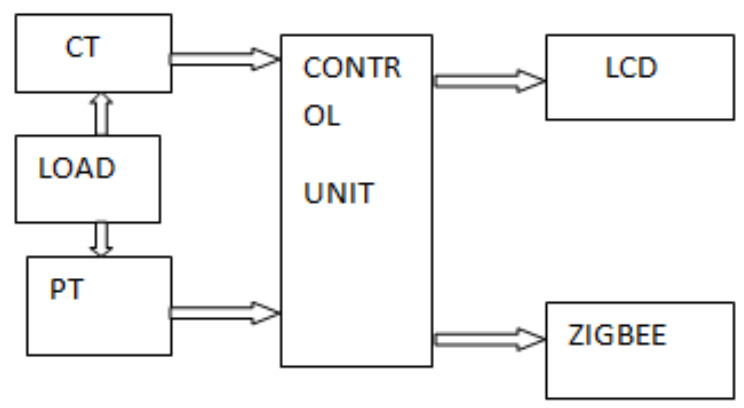

Fig- ENERGY METER AT SUBSCIBER END

The main objective of energy meter is firstly measurement of current using current transformer then measurement of voltage using potential transformer and then by using current and voltage measure the power factor. 
Taking the current, voltage and power factor value as a input to ADC of the controller and then calculating power consumed in watt hours. Using the ADC of the ARM controller, analog data inputs of voltage and current value has been taken. Digital value is generated for both of voltage and current. After that power factor is calculated. After getting all necessary values, the energy consumption is calculated and updated according to the time. Consumed power is displayed on LCD and then by using control module it sends to receiver side using Zigbee module.

\section{C] Zigbee Module-}

Zigbee is the result of the demand from industry and consumer for wireless applications that demand for lower data rate, longer battery life, simple design, shorter range and low cost solutions.

Zigbee is a Low data rate, Low power consumption system operates in Unlicensed Bands. Zigbee ISM 2.4 GHz Global Band operates at 250kbps. This band can be used to Control of lights, switches, thermostats, appliances, etc.

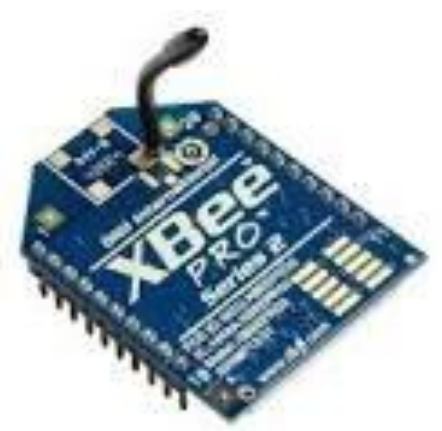

Fig-Zigbee Module

In this system zigbee module is attached to the ARM controller and then according to range of zigbee module sends the information of energy consumed to the receiver zigbee module side. Zigbee module is the best option for sending the information other than bluetooth and Wi-Fi due to range capacity of the module. It reduces the costs of implementation. Zigbee provides strong security capabilities to prevent mischief than other. Zigbee form a complete mesh network so they can communicate with each other .Easily expanded as new homes are built or new services need to be added. In the zigbee communication network, the received signal strength between each transmitter and receiver decides the throughput of communication link.

\section{D] Relay Unit-}

Load is connected to ARM controller via relay. Relay is an electromagnetic switch; consist of a coil, 1 common terminal, 1 normally closed terminal, and one normally open terminal. Relay control unit is used to shutting off the electric power supply when the due date is over. Whenever the user pays the bill the electric power supply is resumed by the relay module. The relay is driven by the LPC2138 controller. Controller of the Wireless meter reading system is a 32bit ARM7 CPU (LPC2138). The system communicates with the remote station through communication module. Depending on the information received from the remote station, the LPC2138 can control the Relay module to shut off or resume the electric power supply

\section{E] Mobile Section-}

A mobile phone also known as a wireless phone, cell phone, or cellular telephone is a little portable radio telephone. Mobile Phone can serve as powerful tool for world-wide communication. The Mobile Phone is a natural choice, since it is a communication resource generally available by people, which makes them practically always contactable and capable to send billing information. All the information of energy consumed and send bill message to the customer \& also send the deadline for the paying bill.

\section{Conclusion}

In this wireless meter reading system is designed to monitor the meter reading and send the reading to customer. It provides correct meter reading, avoid the billing error and reduce the maintenance cost. It displays the information of bill on mobile for user notification. This provides an application in the field of automatic electric meter reading system. This project has thus provided a simple, accurate and useful solution in the form of the wireless digital energy meter. 


\section{Reference}

[1]. L. Shiwei, etc, "Design of an automatic meter reading system," Proceedings of the 1996 IEEE IECON 22nd International Conference on Industrial Electronics, pp.631-636, Aug. 1996

[2]. Liting Cao, Jingwen Tian and Dahang Zhang, "Networked Remote Meter-Reading System Based on Wireless Communication Technology" in International Conference on Information Acquisition, 2006 IEEE.

[3]. Liting Cao, Wei Jiang, Zhaoli Zhang "Automatic Meter Reading System Based on Wireless Mesh Networks and SOPC Technology" in International Conference on Intelligent Networks and Intelligent Systems, 2009 IEEE.

[4]. Baronti P, Pillai P, Chook V, Chessa S, Gotta A, Hu Y. Wireless sensor networks: A survey on the state of the art and the 802.15.4 and ZigBee standards. Computer Communications 2007; 30: 1655-1695.

[5]. Bo Chen, Mingguang Wu, Shuai Yao, and Ni Binbin,2009 IEEE." ZigBee Technology And Its Application On Wireless Meter Reading System".

[6]. Chun-senXU,Xiang-jian CHEN, Di LI, Xiu-hong Zhong,2008 IEEE, “Automatic Electric Meter Reading System Based On ZigBee

[7]. Subhashis Maitra, 2008 IEEE, “ Embedded Energy Meter- A New Concept To Measure The Energy Consumed By A Consumer And To Pay The Bill 